\title{
First-line immune checkpoint inhibitors for patients with metastatic urothelial carcinoma treated in routine clinical practice
}

\author{
Renato Naito, Kouji Izumi, Atsushi Mizokami \\ Department of Integrative Cancer Therapy and Urology, Kanazawa University Graduate School of Medical Science, Kanazawa, Ishikawa, Japan \\ Correspondence to: Dr. Kouji Izumi. Department of Integrative Cancer Therapy and Urology, Kanazawa University Graduate School of Medical \\ Science, 13-1 Takaramachi, Kanazawa, Ishikawa 920-8640, Japan. Email: azuizu2003@yahoo.co.jp. \\ Provenance and Peer Review: This article was commissioned and reviewed by the Section Editor Xiao Li, MD (Department of Urology, Jiangsu Cancer \\ Hospital \& Jiangsu Institute of Cancer Research \& Nanjing Medical University Affiliated Cancer Hospital, Nanjing, China). \\ Comment on: Feld E, Harton J, Meropol NJ, et al. Effectiveness of First-line Immune Checkpoint Blockade Versus Carboplatin-based Chemotherapy \\ for Metastatic Urothelial Cancer. Eur Urol 2019;76:524-32.
}

Submitted Jan 28, 2020. Accepted for publication Apr 10, 2020.

doi: $10.21037 /$ tau.2020.04.08

View this article at: http://dx.doi.org/10.21037/tau.2020.04.08

Patients with advanced or metastatic urothelial carcinoma are generally older and nephroureterectomy is frequently performed in such patients; therefore, cisplatin-based regimen often cannot be applied because of renal insufficiency and poor performance status. Gemcitabine and carboplatin is frequently used as combination chemotherapy for cisplatin-unfit patients and to reduce toxicities. Meanwhile, immune checkpoint inhibitors may be used to reduce toxicities without an efficacy compromise because immune checkpoint inhibitors are available regardless of renal function. The retrospective cohort study conducted by Feld et al. (1) clearly demonstrated inferior short-term but superior long-term survival with first-line immune checkpoint inhibitors relative to carboplatin-based chemotherapy among patients with metastatic urothelial carcinoma treated in routine clinical practice.

Urothelial carcinoma is the sixth most common cancer in the United States, accounting for approximately 3\% of cancer-related deaths (2). For advanced or metastatic urothelial carcinoma, platinum-based combination chemotherapy is the standard first-line treatment. In 1992, methotrexate, vinblastine, doxorubicin, and cisplatin (MVAC) was established as the first standard combination chemotherapy (3). Subsequently, gemcitabine and cisplatin (GC), which showed less adverse events and was as effective as MVAC, was recognized as the new standard combination chemotherapy in 2005 for advanced or metastatic urothelial carcinoma, and currently holds the same position (4).
Unfortunately, after platinum-based chemotherapy, disease progression was frequently observed, and the overall survival (OS) rate at 2 years in patients treated with GC was only approximately $30 \%$; moreover, most patients required a second-line treatment (5). The development of a better treatment strategy has been attempted in the past decade.

Several molecular targeting agents and immune checkpoint inhibitors, such as programmed death-1 (PD-1) and programmed death-ligand 1 (PD-L1) antibodies, have been tested to establish a standard second-line treatment $(6,7)$. The KEYNOTE-045, phase 3 randomized-controlled trial revealed that the PD-1 antibody pembrolizumab significantly prolonged the OS of patients after platinumbased combination chemotherapy treatment (7). High tolerability and reduced adverse event frequency were noted during PD-1 and PD-L1 antibody treatment (8-11). Patients with advanced or metastatic urothelial carcinoma are generally older and nephroureterectomy is frequently performed in such patients; therefore, cisplatin-based regimen, such as MVAC and GC, often cannot be applied because of renal insufficiency and poor performance status. For such patients, immune checkpoint inhibitors may be used to reduce toxicities without an efficacy compromise because immune checkpoint inhibitors are available regardless of renal function $(12,13)$. Hence, we reviewed multicenter studies reporting the use of immune checkpoint inhibitors as the first-line therapy for patients with advanced or metastatic urothelial cancer who are ineligible 
for cisplatin $(12,13)$.

The KEYNOTE-052 trial with a 5 -month median follow-up period revealed that $24 \%$ of patients treated with pembrolizumab achieved either a complete or partial response, $23 \%$ achieved stable disease, and $62 \%$ experienced adverse events with $16 \%$ having $\geq$ grade 3 adverse events. Gemcitabine and carboplatin (GCarbo) is frequently used as combination chemotherapy for cisplatin-unfit patients and to reduce toxicities (14). Compared to carboplatin-based chemotherapy, pembrolizumab tends to be superior for low toxicity and its efficacy in elderly patients (14). In the IMVigor-210 trial (13) that had a long median follow-up period (17.2 months), the objective response rate was $23 \%$ and a complete response was achieved in $9 \%$ of patients treated with atezolizumab. The median progression-free survival was 2.7 months, median OS was 15.9 months, and 12 -month survival rate was $57 \%$. In particular, patients who achieved stable disease had a prolonged median OS of 19.1 months. The OS was considerably longer than the median OS of patients treated with GCarbo (9.3 months) (14). Patients who received atezolizumab and GC revealed a similar median OS of 15.2-15.8 months $(5,15)$. Regarding adverse events, GCarbo was reported to induce severe acute toxicity in $9 \%$ of patients characterized by grade 4 thrombocytopenia with bleeding, febrile neutropenia, $\geq$ grade 3 mucositis causing death, and $\geq$ grade 3 renal toxicity (14). Adverse events that were $\geq$ grade 3 were observed in more than half of the patients; neutropenia was the most common at $52.5 \%$ (14). Moreover, the most common $\geq$ grade 3 adverse event observed in patients who received GC was neutropenia (71\%), followed by thrombocytopenia (57\%) (5). These results suggest that immune checkpoint inhibitors can be safely administered, leading to fewer adverse events than conventional chemotherapy.

In June 2018, the US Food and Drug Administration restricted the use of pembrolizumab and atezolizumab in patients with advanced or metastatic urothelial carcinoma who were unfit for platinum-based chemotherapy and have low PD-L1 expressions (16). The decision was based on the early results of the ongoing phase 3 trial, and it is likely that the conclusion will remain the same. Furthermore, the GC split, wherein the cisplatin dose is split for days 2 and 3 or days 2 and 9, showed better efficacy than GCarbo in cisplatin-unfit patients with advanced or metastatic urothelial carcinoma (17).

Through a single-arm phase 2 study, immune checkpoint inhibitors have been approved; however, few studies have directly compared carboplatin-based chemotherapy to immune checkpoint inhibitors. Using a large sample size of >2,000 patients, Feld et al. evaluated and compared the effectiveness of first-line immune checkpoint inhibitors and carboplatin-based chemotherapy for metastatic urothelial cancer (1). Table 1 shows a summary of open data in studies of first line immune checkpoint inhibitor for metastatic urothelial carcinoma $(1,12,13,18,19)$. The immune checkpoint inhibitor group had a lower survival rate than the carboplatin-based chemotherapy group at 12 months of treatment; however, the immune checkpoint inhibitor group showed a higher survival rate at 36 months, crossing the Kaplan-Meier curves (1). Interestingly, the immune checkpoint inhibitor curve showed a flat long tail at 30\% after 24 months. Patients who survived the first 1-2 years of immune checkpoint inhibitor treatment were expected to show long-term survival (1). Although the relationship between PD-L1 expression and response rate of immune checkpoint inhibitors is unclear, patients positive for PDL1 and treated with immune checkpoint inhibitors have shown the longest survival, whereas those negative for PDL1 and treated with immune checkpoint inhibitors have the shortest survival. This indicates that the therapeutic effect may be predicted through PD-L1 expression at the time of treatment initiation (1). However, in this realworld study, there may be some limitations. As mentioned, the patient background was unclear; the fact that the site of metastasis or comorbidity was not evaluated may have critically affected patient survival (1). Moreover, Galsky et al. established the definitions of patients with metastatic urothelial carcinoma who are unfit for cisplatin-based chemotherapy: (I) WHO or Eastern Cooperative Oncology Group performance status of 2 or Karnofsky performance status of $60-70 \%$; (II) creatinine clearance (calculated or measured) $<1 \mathrm{~mL} / \mathrm{s}$; (III) common terminology criteria for adverse events (CTCAE) version 4 , grade $\geq 2$ audiometric hearing loss; (IV) CTCAE version 4 , grade $\geq 2$ peripheral neuropathy; and (V) New York Heart Association class III heart failure (20); however, there were no clear criteria for cisplatin ineligibility in this study (1). Furthermore, there were some patients who received cisplatin as a second-line treatment; therefore, this result may not be considered as the outcome of immune checkpoint inhibitor treatment for cisplatin-unfit patients (1). This retrospective cohort study had some limitations that require careful attention for better understanding; however, the study clearly demonstrated inferior short-term but superior long-term survival with first-line immune checkpoint inhibitors 
Table 1 The comparison of immune checkpoint inhibitors for urothelial carcinoma

\begin{tabular}{|c|c|c|c|c|c|}
\hline Variable & $\begin{array}{l}\text { KEYNOTE-052 } \\
\text { (12) }\end{array}$ & $\begin{array}{l}\text { IMVigor-210 } \\
\text { (13) }\end{array}$ & $\begin{array}{c}\text { KEYNOTE-361 } \\
\text { (18) }\end{array}$ & $\begin{array}{l}\text { IMVigor-130 } \\
\qquad(19)\end{array}$ & Feld et al. (1) \\
\hline Type of study & Prospective & Prospective & Prospective & Prospective & Retrospective \\
\hline Status of study & Complete & Complete & Ongoing & Ongoing & Complete \\
\hline $\mathrm{ICl}$ & Pembrolizumab & Atezolizumab & Pembrolizumab & Atezolizumab & $\begin{array}{l}\text { Nivolumab, pembrolizumab, } \\
\text { atezolizumab, durvalumab, avelumab }\end{array}$ \\
\hline Comparison & Single arm & Single arm & $\begin{array}{l}\mathrm{ICl}+\mathrm{GC} \text { vs. } \\
\mathrm{ICl} \text { vs. GC }\end{array}$ & $\begin{array}{l}\mathrm{ICl}+\mathrm{GC} \text { vs. } \\
\mathrm{ICl} \text { vs. GC }\end{array}$ & $\mathrm{ICI}$ vs. carboplatin-based \\
\hline No. of patients & 370 & 119 & 990 & 1,200 & 487 \\
\hline Age $\geq 80$ years $(\%)$ & 29 & 21 & $\mathrm{~N} / \mathrm{A}$ & $\mathrm{N} / \mathrm{A}$ & $\mathrm{N} / \mathrm{A}$ \\
\hline ECOG PS2 (\%) & 41 & 27 & N/A & N/A & 27 \\
\hline \multicolumn{6}{|l|}{ Primary location (\%) } \\
\hline Upper UT & 19 & 28 & N/A & N/A & 25 \\
\hline Lower UT & 81 & 71 & N/A & N/A & 75 \\
\hline Median follow up (months) & 5 & 17.2 & $\mathrm{~N} / \mathrm{A}$ & $\mathrm{N} / \mathrm{A}$ & 7.2 \\
\hline Median PFS (months) & 2 & 2.7 & N/A & $\mathrm{N} / \mathrm{A}$ & $\mathrm{N} / \mathrm{A}$ \\
\hline Median OS (months) & N/A & 15.9 & $\mathrm{~N} / \mathrm{A}$ & $\mathrm{N} / \mathrm{A}$ & 9 \\
\hline \multicolumn{6}{|l|}{ Response (\%) } \\
\hline $1-10 \%$ & 52 & N/A & $\mathrm{N} / \mathrm{A}$ & $\mathrm{N} / \mathrm{A}$ & $\mathrm{N} / \mathrm{A}$ \\
\hline ORR & 20 & $\mathrm{~N} / \mathrm{A}$ & $\mathrm{N} / \mathrm{A}$ & $\mathrm{N} / \mathrm{A}$ & $\mathrm{N} / \mathrm{A}$ \\
\hline$>10 \%$ & 30 & N/A & N/A & N/A & 22 \\
\hline ORR & 39 & N/A & N/A & N/A & $\mathrm{N} / \mathrm{A}$ \\
\hline \multicolumn{6}{|l|}{ Infiltrating immune cells (\%) } \\
\hline$<1 \%$ & N/A & 33 & $\mathrm{~N} / \mathrm{A}$ & $\mathrm{N} / \mathrm{A}$ & $\mathrm{N} / \mathrm{A}$ \\
\hline ORR & N/A & 21 & $\mathrm{~N} / \mathrm{A}$ & N/A & N/A \\
\hline $1-5 \%$ & $\mathrm{~N} / \mathrm{A}$ & 40 & N/A & $\mathrm{N} / \mathrm{A}$ & $\mathrm{N} / \mathrm{A}$ \\
\hline ORR & $\mathrm{N} / \mathrm{A}$ & 21 & $\mathrm{~N} / \mathrm{A}$ & $\mathrm{N} / \mathrm{A}$ & $\mathrm{N} / \mathrm{A}$ \\
\hline$>5 \%$ & $\mathrm{~N} / \mathrm{A}$ & 47 & $\mathrm{~N} / \mathrm{A}$ & $\mathrm{N} / \mathrm{A}$ & $\mathrm{N} / \mathrm{A}$ \\
\hline ORR & $\mathrm{N} / \mathrm{A}$ & 28 & N/A & N/A & N/A \\
\hline
\end{tabular}

$\mathrm{ICl}$, immune checkpoint inhibitor; GC, gemcitabine and cisplatin; N/A, not available; ECOG PS, Eastern Cooperative Oncology Group performance status; UT, urinary tract; PFS, progression free survival; OS, overall survival; ORR, overall response rate, PD-L1, programmed death-ligand 1. 
relative to carboplatin-based chemotherapy among patients with metastatic urothelial carcinoma treated in routine clinical practice (1). The percentage of PD-L1 expression in tissue may be a promising biomarker of immune checkpoint inhibitors. Moreover, the decision in administration of immune checkpoint inhibitors may require the high percentage of PD-L1 expression (e.g., $>10 \%$ on the basis of the result of KEYNOTE-052), as already applied in lung cancer clinically on the basis of the result of KEYNOTE-024 $(12,21)$. This study provides important information to facilitate decision-making until the currently pending trial results become available (1).

\section{Acknowledgments}

Funding: None.

\section{Footnote}

Conflicts of Interest: All authors have completed the ICMJE uniform disclosure form (available at http://dx.doi. org/10.21037/tau.2020.04.08). The authors have no conflicts of interest to declare.

Ethical Statement: The authors are accountable for all aspects of the work in ensuring that questions related to the accuracy or integrity of any part of the work are appropriately investigated and resolved.

Open Access Statement: This is an Open Access article distributed in accordance with the Creative Commons Attribution-NonCommercial-NoDerivs 4.0 International License (CC BY-NC-ND 4.0), which permits the noncommercial replication and distribution of the article with the strict proviso that no changes or edits are made and the original work is properly cited (including links to both the formal publication through the relevant DOI and the license). See: https://creativecommons.org/licenses/by-nc-nd/4.0/.

\section{References}

1. Feld E, Harton J, Meropol NJ, et al. Effectiveness of Firstline Immune Checkpoint Blockade Versus Carboplatinbased Chemotherapy for Metastatic Urothelial Cancer. Eur Urol 2019;76:524-32.

2. National Cancer Institute Surveillance, Spidemiology, and End Results Program. SEER cancer statistics factsheets: Bladder cancer. Available online: http://seer.cancer.gov/ statfacts/html/urinb.html (accessed Dec 2, 2019).

3. Loehrer PJ Sr, Einhorn LH, Elson PJ, et al. A randomized comparison of cisplatin alone or in combination with methotrexate, vinblastine, and doxorubicin in patients with metastatic urothelial carcinoma: a cooperative group study. J Clin Oncol 1992;10:1066-73.

4. von der Maase H, Hansen SW, Roberts JT, et al. Gemcitabine and cisplatin versus methotrexate, vinblastine, doxorubicin, and cisplatin in advanced or metastatic bladder cancer: results of a large, randomized, multinational, multicenter, phase III study. J Clin Oncol 2000;18:3068-77.

5. von der Maase H, Sengelov L, Roberts JT, et al. Longterm survival results of a randomized trial comparing gemcitabine plus cisplatin, with methotrexate, vinblastine, doxorubicin, plus cisplatin in patients with bladder cancer. J Clin Oncol 2005;23:4602-8.

6. Petrylak DP, de Wit R, Chi KN, et al. Ramucirumab plus docetaxel versus placebo plus docetaxel in patients with locally advanced or metastatic urothelial carcinoma after platinum-based therapy (RANGE): a randomised, doubleblind, phase 3 trial. Lancet 2017;390:2266-77.

7. Bellmunt J, de Wit R, Vaughn DJ, et al. Pembrolizumab as Second-Line Therapy for Advanced Urothelial Carcinoma. N Engl J Med 2017;376:1015-26.

8. Massard C, Gordon MS, Sharma S, et al. Safety and Efficacy of Durvalumab (MEDI4736), an AntiProgrammed Cell Death Ligand-1 Immune Checkpoint Inhibitor, in Patients With Advanced Urothelial Bladder Cancer. J Clin Oncol 2016;34:3119-25.

9. Rosenberg JE, Hoffman-Censits J, Powles T, et al. Atezolizumab in patients with locally advanced and metastatic urothelial carcinoma who have progressed following treatment with platinum-based chemotherapy: a single-arm, multicentre, phase 2 trial. Lancet 2016;387:1909-20.

10. Sharma P, Callahan MK, Bono P, et al. Nivolumab monotherapy in recurrent metastatic urothelial carcinoma (CheckMate 032): a multicentre, open-label, two-stage, multi-arm, phase 1/2 trial. Lancet Oncol 2016;17:1590-8.

11. Fradet $Y$, Bellmunt J, Vaughn DJ, et al. Randomized phase III KEYNOTE-045 trial of pembrolizumab versus paclitaxel, docetaxel, or vinflunine in recurrent advanced urothelial cancer: results of $>2$ years of follow-up. Ann Oncol 2019;30:970-6.

12. Balar AV, Castellano D, O'Donnell PH, et al. First-line pembrolizumab in cisplatin-ineligible patients with locally advanced and unresectable or metastatic urothelial cancer 
(KEYNOTE-052): a multicentre, single-arm, phase 2 study. Lancet Oncol 2017;18:1483-92.

13. Balar AV, Galsky MD, Rosenberg JE, et al. Atezolizumab as first-line treatment in cisplatinineligible patients with locally advanced and metastatic urothelial carcinoma: a single-arm, multicentre, phase 2 trial. Lancet 2017;389:67-76.

14. De Santis M, Bellmunt J, Mead G, et al. Randomized phase II/III trial assessing gemcitabine/carboplatin and methotrexate/carboplatin/vinblastine in patients with advanced urothelial cancer who are unfit for cisplatinbased chemotherapy: EORTC study 30986. J Clin Oncol 2012;30:191-9.

15. Bellmunt J, von der Maase H, Mead GM, et al. Randomized phase III study comparing paclitaxel/ cisplatin/gemcitabine and gemcitabine/cisplatin in patients with locally advanced or metastatic urothelial cancer without prior systemic therapy: EORTC Intergroup Study 30987. J Clin Oncol 2012;30:1107-13.

16. Food and Drug Administration. FDA limits the use of Tecentriq and Keytruda for some urothelial cancer patients. Available online: https://www.fda.gov/Drugs/ InformationOnDrugs/ApprovedDrugs/ucm612484.htm (accessed Dec 2, 2019).

Cite this article as: Naito R, Izumi K, Mizokami A. Firstline immune checkpoint inhibitors for patients with metastatic urothelial carcinoma treated in routine clinical practice. Transl Androl Urol 2020;9(3):986-990. doi:10.21037/tau.2020.04.08
17. Izumi K, Iwamoto H, Yaegashi H, et al. Gemcitabine Plus Cisplatin Split Versus Gemcitabine Plus Carboplatin for Advanced Urothelial Cancer With Cisplatin-unfit Renal Function. In Vivo 2019;33:167-72.

18. Powles T, Gschwend JE, Loriot Y, et al. Phase 3 KEYNOTE-361 trial: Pembrolizumab (pembro) with or without chemotherapy versus chemotherapy alone in advanced urothelial cancer. J Clin Oncol 2017;35:TPS4590.

19. Galsky MD, Grande E, Davis ID, et al. IMvigor130: A randomized, phase III study evaluating first-line (1L) atezolizumab (atezo) as monotherapy and in combination with platinum-based chemotherapy (chemo) in patients (pts) with locally advanced or metastatic urothelial carcinoma (mUC). J Clin Oncol 2018;36:TPS4589.

20. Galsky MD, Hahn NM, Rosenberg J, et al. A consensus definition of patients with metastatic urothelial carcinoma who are unfit for cisplatin-based chemotherapy. Lancet Oncol 2011;12:211-4.

21. Reck M, Rodríguez-Abreu D, Robinson AG, et al. Pembrolizumab versus Chemotherapy for PD-L1Positive Non-Small-Cell Lung Cancer. N Engl J Med 2016;375:1823-33. 